\title{
The synergistic effects of traditional Chinese herbs and radiotherapy for cancer treatment (Review)
}

\author{
LILI JIA ${ }^{1 *}$, SHUMEI MA ${ }^{1 *}$, XUE HOU ${ }^{1}$, XIN WANG $^{2}$, ABU BAKER LAYTH QASED ${ }^{3}$, XUEFEI SUN ${ }^{2}$, \\ NAN LIANG ${ }^{1}$, HUICHENG LI $^{4}$, HEQING YI ${ }^{1}$, DEJUAN KONG ${ }^{1}$, XIAODONG LIU ${ }^{1,2}$ and FEIYUE FAN ${ }^{5}$ \\ ${ }^{1}$ Key Laboratory of Radiobiology (Ministry of Health), School of Public Health, Jilin University, Changchun 130021; \\ ${ }^{2}$ Department of Radiation Oncology and Radiology, China-Japan Union Hospital, Changchun 130021, \\ ${ }^{3}$ Department of Surgery, Norman Bethune Second Hospital Affiliated to Jilin University, Changchun 130021; \\ ${ }^{4}$ Department of Radiotherapy, Norman Bethune Fourth Hospital Affiliated to Jilin University, Changchun, 130011; \\ ${ }^{5}$ Department of Radiation Hazard Evaluation, Institute of Radiation Medicine of Chinese Academy \\ of Medical Science and Peking Union Medical College, Tianjin 300192, P.R. China
}

Received October 8, 2012; Accepted December 28, 2012

DOI: 10.3892/ol.2013.1245

\begin{abstract}
Traditional Chinese medicine (TCM) has been demonstrated to have potent cytotoxic activity against certain malignant tumors. Ionizing radiation (IR) is one of the most effective methods used in the clinical treatment of cancer. The drawback of a single formula is that it limits the treatment efficacy for cancer, while comprehensive strategies require additional theoretical support. However, a combination of different antitumor treatment modalities is advantageous in restricting the non-specific toxicity often observed with an extremely high dose of a single regimen. The induction of apoptotic cell death is a significant process in tumor cells following radiotherapy or chemotherapy, and resistance to these treatments has been linked to a low propensity for apoptosis. Autophagy is a response of cancer cells to IR or chemotherapy, and involves the prominent formation of autophagic vacuoles in the cytoplasm. In this review, the synergistic effects of TCM and radiotherapy are summarized and the underlying mechanisms are illustrated, providing new therapeutic strategies for cancer.
\end{abstract}

\section{Contents}

1. Introduction

2. Application of TCM in cancer

Correspondence to: $\mathrm{Dr}$ Xiaodong Liu, Key Laboratory of Radiobiology (Ministry of Health), School of Public Health, Jilin University, 1163 Xinmin Street, Changchun 130021, P.R. China E-mail: liuxiaod@jlu.edu.com

*Contributed equally

Key words: traditional Chinese medicine, apoptosis, autophagy, radiosensitization, cancer treatment
3. TCM and radiotherapy

4. TCM, radiosensitivity and apoptosis

5. TCM, radiosensitivity and autophagy

6. Prospects

\section{Introduction}

Ionizing radiation (IR) is widely used in cancer therapy and can induce cell cycle arrest, DNA repair and repair, and/or apoptosis, leading to different biological consequences depending on the cell type. Traditional Chinese medicine (TCM) is often considered to be an alternative or complementary medicine in cancer treatment; it is able to suppress tumor growth and angiogenesis, as well as inhibit invasion and metastasis (1-10). TCMs may also function as a radiosensitizers during the radiotherapy of cancer.

Apoptosis, or type I programmed cell death, is a major response of cancer cells to various therapies including IR and TCM (28-56). Apoptosis is controlled by extrinsic or intrinsic inducers, which often act as targets of TCM to trigger cell death during radiotherapy. Autophagy (type II programmed cell death), a protein degradation system involving the autophagic/lysosomal compartment, is another response of cancer cells to various therapies. The process of autophagy is initiated by the sequestration of a portion of the cytoplasm to form the autophagosome. Subsequently, the autophagosome fuses with the lysosome and the contents of the autophagosome are lyzed. Activation of autophagy in the tumor cells may improve the outcome of radiotherapy. The roles of TCM in radiation-induced cell death determine the application of TCM in cancer treatment.

\section{Application of TCM in cancer}

TCM has been used for thousands of years. The majority of Chinese herbal formulae comprise several herbal components and have been used to treat various chronic diseases, mainly by 
immunomodulation or by altering inducible cell death.Although TCM has assigned anticancer activities, the underlying mechanisms are not well understood. Certain herbs are able to inhibit the migration and invasion of cancer cells in vitro, while others trigger apoptosis in cancer cells. The herbs used in TCMs for treating human cancer are summarized in Table I (1-10).

\section{TCM and radiotherapy}

A series of studies concerning the radioprotective and radiosensitizing functions of TCM have been conducted over a long time period. In the 20th century, scientists focused on testing the radioprotective effects of TCM in experimental animals. A series of bioactive components were isolated from TCMs and the mechanisms of radioprotection were studied. Improving the function of the hematopoietic and immune systems may be characteristic of such TCM herbs.

Kuei-Pi-Tang is a type of TCM that has been suggested to have therapeutic effects on hemato-deficient diseases and radiation-related injuries. Kuei-Pi-Tang has been demonstrated to increase the recovery of cellular immunocompetence, particularly when administered at a concentration of $20 \mathrm{mg} / 20 \mathrm{~g}$ body weight following $\gamma$-ray irradiation (11). Additionally, Ren-Shen-Yang-Rong-Tang, Zaizhang-I (ZZ-I) and Juzen-Taiho-Toh (TJ-48) have demonstrated effects on the hematopoietic recovery from radiation-related injury in mice, by stimulating hematopoietic stem cells and by improving the hematopoietic inductive microenvironment (HIM). The results demonstrated that these TCM herbs significantly promoted the recovery of the colony-forming unit-spleen (CFU-S) and the colony-forming unit-granulocyte/macrophage (CFU-GM) (12-14). Furthermore, Gynostemma pentaphyllum (Gp) has been shown to assist in the recovery of decreased leukocyte counts, GOT, GPT and IgG serum levels, and the proliferation of splenocytes stimulated by PHA, LPS and Con A in $\gamma$-ray-irradiated mice (15). Moreover, Dang-Gui-Shao-Yao-San (DGSYS), administered to previously X-irradiated mice increased the number of CFU-S in the mice that survived the irradiation, as well as significantly ameliorating leukopenia, thrombocytopenia and the depression of hematocrits following irradiation (16). In addition, certain TCMs have been demonstrated to increase immunocompetence in $\gamma$-ray-irradiated mice; Ganoderma lucidum (GI) and Krestin (PSK) increased the splenic weight and leukocyte count following $\gamma$-ray irradiation (17). Furthermore, Si-Wu-Tang was observed to protect the jejunal crypts, increase the formation of endogenous spleen colonies and reduce the frequency of radiation-induced apoptosis when administered prior to irradiation; while extracts of Danggui and Baishaoyao have been revealed to have potentially significant radioprotective effects (18).

Throughout the 21st century, numerous scientists have begun to administer TCM herbs as an adjunct to radiotherapy/chemotherapy for certain types of cancer. We discuss examples of such herbs used in radiotherapy. TCM has been shown to exhibit radiomodifying effects on tumors and normal tissues by in vitro and in vivo studies. A number of these agents are able to enhance the therapeutic gain of radiotherapy by acting as radiosensitizers to the tumor cells and/or as radioprotectors to normal cells. Botanical agents are comprised of multiple phytochemical compounds that may work individually or synergistically to not only improve the outcomes of radiotherapy, but also to induce a variety of anticancer effects. It is important to evaluate these botanical agents for their efficacy, tumor specificity and safety profiles during radiotherapy (19). The goji berry, Lycium barbarum, is well-recognized in TCM for its various therapeutic properties based on its antioxidant and immunomodulating effects. A previous study demonstrated the antioxidant activity of the goji berry in the skin; 5\% goji berry juice provided significant protection against lipid peroxidation induced by UVA radiation. Two known inducible endogenous skin antioxidants, haem oxygenase-1 and metallothionein, were found to be involved in the photoimmune protection. Therefore, goji berry juice has the potential to provide additional photoprotection for susceptible humans (20). Studies have also demonstrated that TCM herbs are able to protect hematopoietic organs against radiation-induced damage. For example, panaxatriol (PT) has been observed to relieve myelosuppression induced by radiation injury. The ability of the agent to regulate the expression of the hematopoietic growth factor GM-CSF and to promote the maturation of bone marrow cells may be responsible for a number of these beneficial effects (21). Additionally, the effects of the main ingredients of Bu-Zhong-Yi-Qi-Tang on jejunal crypt survival, endogenous spleen colony formation and apoptosis in jejunal crypt cells were investigated in mice irradiated with high and low doses of $\gamma$-rays (22).

IR is capable of inducing DNA damage and cell death by generating reactive oxygen species (ROS). Pre-treatment of thymocytes with paeoniflorin (PF) has been demonstrated to reverse this tendency and to attenuate irradiation-induced ROS generation. Several antiapoptotic characteristics of PF, including the ability to diminish cytosolic $\mathrm{Ca}^{2+}$ concentration, inhibit caspase-3 activation, upregulate $\mathrm{Bcl}-2$ and downregulate Bax in 4-Gy-irradiated thymocytes, have been identified. $\mathrm{PF}$ was also observed to block extracellular signal-regulated kinase (ERK), c-Jun N-terminal kinase (JNK) and p38 kinase, which were activated by 4-Gy irradiation (23). Furthermore, in human dermal fibroblasts, berberine (BBR) was able to decrease UV-induced MMP-1 expression and reverse $\mathrm{UV}$-induced reduction of type I procollagen in a dose-dependent manner (24). Additionally, an isoflavone extract from soybean cake decreased UVB-induced HaCaT cell death and the phosphorylation of $\mathrm{p} 38, \mathrm{JNK}$ and ERK1/2 in vitro. In the in vivo studies, topical application of isoflavone extract prior to UVB irritation decreased the epidermal thickness and the expression levels of COX-2 and PCNA, and increased the catalase concentration (25). Moreover, the Chinese herbal preparation, Yangyin Humo Decoction (YHD), was able to alleviate the oral mucomembranous reaction to radiation applied to patients with head-neck tumors (26). In addition, aloe polysaccharides (AP) have demonstrated radioprotective effects by blocking the upregulation of pro-apoptotic p53, Bax and $\mathrm{Bad}$, and the downregulation of $\mathrm{Bcl}-2$, in normal human cells in vitro and in mice in vivo (27).

\section{TCM, radiosensitivity and apoptosis}

Apoptosis is one of the processes of programmed cell death (PCD) that occurs in multicellular organisms, where biochem- 
Table I. Summary of reported effects on human cancer following TCM administration.

\begin{tabular}{|c|c|c|c|c|}
\hline TCM & Cancer & Effect & Pathway & Reference \\
\hline Yanhusuo & Breast cancer & $\begin{array}{l}\text { Inhibits migration and } \\
\text { invasion }\end{array}$ & $\begin{array}{l}\text { Activates p38; } \\
\text { inhibits ERK1/2 and } \\
\text { ASPK/JNK (MAPKs) }\end{array}$ & (1) \\
\hline Celastrol & Prostate cancer & $\begin{array}{l}\text { Suppresses tumor } \\
\text { growth and angiogenesis }\end{array}$ & AKT/mTOR/p70S6K & (2) \\
\hline Icariin & Gastric cancer & $\begin{array}{l}\text { Inhibits migration } \\
\text { and invasion }\end{array}$ & $\begin{array}{l}\text { Rac1-dependent } \\
\text { VASP pathway }\end{array}$ & (3) \\
\hline \multirow[t]{2}{*}{ Tanshinone IIA } & Cervical cancer & $\begin{array}{l}\text { Inhibits invasion } \\
\text { and metastasis }\end{array}$ & $\begin{array}{l}\mathrm{G} 2 / \mathrm{M} \text { arrest and } \\
\text { subsequent apoptosis }\end{array}$ & $(4,5)$ \\
\hline & Hepatocellular cancer & $\begin{array}{l}\text { Inhibits invasion } \\
\text { and metastasis }\end{array}$ & $\begin{array}{l}\text { Inhibits MMP2, } \\
\text { MMP9 and NF-кB }\end{array}$ & \\
\hline Berbamine & Lung cancer & $\begin{array}{l}\text { Suppresses growth } \\
\text { and migration }\end{array}$ & $\begin{array}{l}\text { Reduces } \mathrm{Bcl}-2 / \mathrm{Bax} \\
\text { protein ratio }\end{array}$ & (6) \\
\hline GSPP & Hepatoma & $\begin{array}{l}\text { Inhibits proliferation } \\
\text { and migration }\end{array}$ & $\begin{array}{l}\text { S phase arrest; } \\
\text { calcium-mediated regulation } \\
\text { of the actin cytoskeleton } \\
\text { reorganization }\end{array}$ & (7) \\
\hline Gecko & Esophageal cancer & Inhibits growth & $\begin{array}{l}\text { Apoptosis; } \\
\text { downregulation of } \\
\text { VEGF and bFGF } \\
\text { protein expression }\end{array}$ & (8) \\
\hline Ganodema & Colorectal cancer & Inhibits growth & $\mathrm{G} 2 / \mathrm{M}$ arrest & (9) \\
\hline DATS & Osteosarcoma cancer & $\begin{array}{l}\text { Suppresses cell } \\
\text { proliferation }\end{array}$ & $\begin{array}{l}\text { G0/G1 phase arrest; } \\
\text { induces apoptosis }\end{array}$ & (10) \\
\hline
\end{tabular}

ical events lead to characteristic cell changes and death. In addition to the significance of apoptosis as a biological phenomenon, defective apoptotic processes have been implicated in numerous types of diseases. Excessive apoptosis causes atrophy, as in the case of ischemic damage; whereas an insufficient level of apoptosis results in uncontrolled cell proliferation, such as in cancer. TCMs act in cancer via various effects and pathways (Tables II, III and IV) (28-56).

Radiosensitive cells have been demonstrated to correlate with a good outcome following radiotherapy. An increased understanding of the molecular processes underlying cellular sensitivity to IR has led to the identification of novel targets for intervention. A combination of a monoclonal antibody (TRA-8) to the human death receptor (DR5) and IR enhanced radiosensitivity in the human radioresistant larynx squamous carcinoma cell line, providing an effective treatment strategy for patients with radioresistant cancers (57). Additionally, wortmannin combined with X-rays inhibited DNA-dependent protein kinase (DNA-PK), resulting in the inhibition of double-strand break (dsb) repair in the fast component. This effect enhanced the induction of apoptosis during the radiosensitization of bladder tumors (58). Moreover, increased levels of heat shock protein (Hsp) 27 and 70 have been identified to be closely correlated with tumorigenesis, metastasis, resistance to anticancer therapeutics and thus a poor prognosis in a wide range of tumors. Silencing of Hsp27 and Hsp70 has both enhanced radiation sensitivity and amplified irradiationinduced apoptosis (59). Certain agents have demonstrated their ability to inhibit antiapoptotic proteins of the Bcl-2 and caspase families on exposure to radiation, thus enhancing the radiation sensitivity. Exploration of the clinical applications of these agents as radiosensitizers for tumor therapy is merited (60-68). Simultaneous inhibition of STAT3 and ErbB2 has been demonstrated to induce U251 cell apoptosis, which was primarily associated with the mitochondrial apoptotic pathway and radiosensitizing activity in human glioma (69).

The HDAC inhibitor, valproic acid (VPA), which enhances IR-induced mitochondrial localizations of Bax and Bcl-xL, was observed to upregulate the mitochondrial membrane potential and be involved in the release of cytochrome $c$ only 
Table II. Summary of reported actions of TCM in apoptosis through Fas/FasL.

\begin{tabular}{llll}
\hline TCM & \multicolumn{1}{c}{ Cancer } & \multicolumn{1}{c}{ Effect } & \multicolumn{1}{c}{ Pathway } \\
\hline KLT & Hepatoma & Apoptosis & Fas/FasL; \\
& & & G2/M arrest \\
Berbamine & Hepatoma & Apoptosis & Fas/FasL \\
Waltonitone & Hepatoma & Inhibits growth; & Fas/FasL; \\
& Breast cancer & apoptosis & mitochondria pathway \\
Celastrol & Pancreatic cancer & Apoptosis & TRAIL \\
Cantharidin & G2/M arrest; & JNK \\
Genistein & apoptosis & Fas/FasL; \\
& & Apoptosis & mitochondria pathway \\
\hline
\end{tabular}

TCM, traditional Chinese medicine; KLT, Kang-Lai-Te; Fas, TNF receptor superfamily; FasL, Fas ligand; TRAIL, TNF-related apoptosis-inducing ligand; JNK, c-Jun N-terminal kinase.

Table III. Summary of reported actions of TCM in apoptosis through the mTOR pathway.

\begin{tabular}{|c|c|c|c|c|}
\hline TCM & Cancer & Effect & Pathway & Reference \\
\hline Osthole & Breast cancer & Inhibits proliferation & $\begin{array}{l}\text { AKT/mTOR; } \\
\text { induces apoptosis }\end{array}$ & (34) \\
\hline SYUNZ-16 & Hepatoma & $\begin{array}{l}\text { Inhibits growth } \\
\text { Apoptosis }\end{array}$ & $\begin{array}{l}\mathrm{PKB} / \mathrm{AKT} \\
\mathrm{AKT} / \mathrm{FOXO}\end{array}$ & (35) \\
\hline Casticin & Leukemia & Apoptosis & PI3K/AKT & (36) \\
\hline AECM & Breast cancer & Apoptosis & AKT & (37) \\
\hline Antroquinonol & Hepatoma & $\begin{array}{l}\text { G1 arrest; } \\
\text { apoptosis }\end{array}$ & $\begin{array}{l}\text { AMPK } \\
\text { mTOR }\end{array}$ & (38) \\
\hline
\end{tabular}

TCM, traditional Chinese medicine; AECM, aqueous extract of Cordyceps militaris; AKT, v-akt murine thymoma viral oncogene homolog 1; mTOR, mammalian target of rapamycin; PKB, protein kinase B; FOXO, forkhead box; PI3K, phosphoinositide-3-kinase.

in wild-type p53 cell lines. It was also found to enhance the radiotherapy response in colorectal cancer, particularly in tumors with the wild-type p53 genotype (70). p53-upregulated modulator of apoptosis (PUMA), is a Bcl-2 homology 3 (BH3)-only Bcl-2 family member that directly binds and antagonizes all known antiapoptotic Bcl-2 family members to induce mitochondrial dysfunction and caspase activation (71). Additionally, Ser46 phosphorylation of p53 has been demonstrated to induce coincident caspase-7 and PARP cleavage in response to IR. Furthermore, mutation of p53 (Ser46) to alanine attenuated IR-induced apoptotic signaling, and ought, therefore, to be a target for radiosensitization (72). Moreover, inhibition of Bcl-xL expression has been observed to result in potent antitumor activity and radiosensitization in human prostatic carcinoma (73).

Certain TCM herbs act as radioprotective or radiosensitizing agents via apoptotic pathways. Treatment with a combination of arsenic trioxide and irradiation has been shown to enhance the apoptotic effects in U937 cells through increased mitotic arrest and ROS generation accompanied by a decrease in Bcl-2 and Bcl-xL levels, and upregulation of caspase-3 levels (74). In addition, a water-soluble ginseng (Panax root) extract was observed to provide greater protection against radiation-induced DNA damage than isolated ginsenoside fractions (saponins). The underlying radioprotective mechanism of ginseng may be linked, directly or indirectly, to its antioxidative capability by the free radicals responsible for DNA damage. Ginseng is considered to be a promising radioprotector in therapeutic or preventive protocols that is able to attenuate the deleterious effects of radiation in human normal tissue, particularly in cancer patients undergoing radiotherapy $(75)$.

\section{TCM, radiosensitivity and autophagy}

Autophagy, also known as type II programmed cell death or autophagocytosis, is a catabolic process involving the degradation of cellular components through the lysosomal machinery. It is a tightly regulated process that occurs naturally in cell growth, development and homeostasis, and assists in main- 
Table IV. Summary of reported actions of TCM in apoptosis through the Bcl-2 family.

\begin{tabular}{|c|c|c|c|c|}
\hline TCM & Cancer & Effect & Pathway & Reference \\
\hline Toona sinensis & Lung cancer & G1 arrest; apoptosis & $\mathrm{Bcl}-2$ & (39) \\
\hline ApoG2 & Hepatoma & Apoptosis & Bcl-2; Bcl-xL; caspase-3 & $(40)$ \\
\hline Baicalin & Breast cancer & G0/G1 arrest; apoptosis & Bax & $(41)$ \\
\hline $\mathrm{As}_{2} \mathrm{O}_{3}$ & Neuroblastoma & Apoptosis & Bcl-2; Bid; Bcl-xL & $(42)$ \\
\hline Bufotalin & Hepatoma & G1 arrest; apoptosis & AIF caspase & (43) \\
\hline GA3 & Leukemia & Apoptosis & Bcl-2; Bax & (44) \\
\hline GA & Malignant melanoma & Apoptosis & Bcl-2; Bax; caspase-3 & $(45)$ \\
\hline ON-III & Breast cancer & Apoptosis & Bim & (46) \\
\hline Rhein & Tongue cancer & $\mathrm{S}$ arrest; apoptosis & Bcl-2; Bax; caspase-3 & (47) \\
\hline PSI & Ovarian cancer & $\mathrm{G} 2 / \mathrm{M}$ arrest; apoptosis & $\begin{array}{l}\text { Bcl-2; Bax; } \\
\text { caspase-3 and -9 }\end{array}$ & $(48)$ \\
\hline Corosolic & Cervix adenocarcinoma & $\mathrm{S}$ arrest; apoptosis & $\begin{array}{l}\text { Bcl-2; Bax; } \\
\text { caspase- } 3,-8 \text { and }-9\end{array}$ & (49) \\
\hline Alpinia pricei rhizome & Oral epithelium carcinoma & Apoptosis & $\begin{array}{l}\text { Bcl-2; Bax; } \\
\text { caspase-3 and -9 }\end{array}$ & $(50)$ \\
\hline Cinobufacini & Hepatoma & Apoptosis & $\begin{array}{l}\text { Bcl-2; Bax; } \\
\text { caspase-3 and -9; } \\
\text { mitochondria pathway }\end{array}$ & $(51)$ \\
\hline Houttuynia cordata Thunb & Colon adenocarcinoma & Apoptosis & $\begin{array}{l}\text { Bcl-2; Bax; } \\
\text { mitochondria pathway }\end{array}$ & $(52)$ \\
\hline DHA & Lung cancer & Apoptosis & Caspase-3 & $(53)$ \\
\hline Plumbagin & Pancreatic cancer & Apoptosis & $\begin{array}{l}\text { Bcl-2; Bax; } \\
\text { caspase- } 3,-8 \text { and }-9\end{array}$ & (54) \\
\hline $\mathrm{CPBF}$ & Cervix adenocarcinoma & Apoptosis & $\begin{array}{l}\text { Bcl-2; Bax; } \\
\text { caspase-3 and -9; } \\
\text { mitochondria pathway }\end{array}$ & $(55)$ \\
\hline ART & T leukemia & Apoptosis & Bcl-2; ROS & $(56)$ \\
\hline
\end{tabular}

taining a balance between the synthesis, degradation and subsequent recycling of cellular products. It is a key mechanism by which a starving cell reallocates nutrients from unnecessary processes to more essential processes. It is unknown whether the autophagic activity in dying cells itself causes death or whether it simply occurs as a process alongside it. A cell may either die or survive, and these two outcomes are dependent on environmental factors. It is unclear whether the increase in autophagosomes indicates an increase in autophagic activity or a decrease in autophagosome-lysosome fusion (76).

Many signal pathways participate in the process of autophagy. Mammalian target of rapamycin (mTOR) senses nutrient, metabolic and hormonal signals and is involved in numerous regulatory events associated with energy metabolism, including the nuclear localization of nutrientregulated transcription factors. mTOR is abundantly expressed when nutrients are plentiful and it suppresses autophagy.
Phosphoinositide-3-kinase I (PI3KI)/AKT is an upstream regulator of mTOR and p70S6 kinase is the downstream effector of mTOR, PI3KI/AKT-mTOR-p70S6 kinase signaling represses the process of autophagy. Additionally, Beclin 1 represents an important component of the autophagic machinery; it interacts with proteins that positively regulate autophagy, such as Vps34, UVRAG and Ambra1, as well as with antiapoptotic proteins such as Bcl-2 (via its $\mathrm{BH} 3$-like domain) to negatively regulate autophagy (77). Beclin 1 acts as a part of the class III PI3K (PI3KIII) Vps34 complex that induces autophagy (78). The Bcl-2 families are also regulators of autophagy; Bcl-xL, which normally protects cells from autophagy by inhibiting the Beclin-1/Vps34 complex, is essential for autophagy (79). Bax and Bak, which act as a gateway for caspase-mediated cell death, also function as downregulators of autophagy (80).

Several regulators of the apoptotic pathway, such as PI3K/Akt signaling, p53 and Bcl-2 family members, also 
Table V. Summary of reported actions of TCM in tumors through the mTOR pathway, by inducing or potentially inducing autophagy.

\begin{tabular}{lllll}
\hline TCM & Cancer & & Effect & Pathway \\
\hline Licorice & Prostate & Induces autophagy & mTOR & Reference \\
Alisol B & Gastrc & Induces autophagy & CaMKK-AMPK-mTOR & $(85)$ \\
Osthole & Breast & Inhibits proliferation; induces autophagy & AKT/mTOR & $(34)$ \\
SYUNZ-16 & Hepatoma & Inhibits growth autophagy & PKB/AKT; AKT/FOXO & $(35)$ \\
Casticin & Leukemia & Autophagy & PI3K/AKT & $(36)$ \\
AECM & Breast & Autophagy & AKT & $(37)$ \\
Antroquinonol & Hepatoma & G1 arrest; autophagy & AMPK; mTOR & $(38)$
\end{tabular}

TCM, traditional Chinese medicine; AECM, aquenous extract of Cordyceps militaris; mTOR, mammalian target of rapamycin; CaMKK, calcium/calmodulin-dependent protein kinase kinase; AMPK, AMP-activated protein kinase; AKT, v-akt murine thymoma viral oncogene homolog 1; PKB, protein kinase B; FOXO, forkhead box; PI3K, phosphoinositide-3-kinase.

function as modulators of autophagy. Taking Bcl-2 as an example, Beclin 1 is capable of binding to PI3KIII as well as to $\mathrm{Bcl}-2$, and the $\mathrm{Bcl} 2$-Beclin complex inhibits the process of autophagy, while the dissociation of Beclin 1 from its Bcl-2 inhibitor is essential for its autophagic activity. DAPK is able to phosphorylate Beclin 1 at Thr119, which is located at a crucial position within its $\mathrm{BH} 3$ domain, and thus promote the dissociation of Beclin 1 from Bcl-xL and the induction of autophagy (81). Therfore, there may be a 'molecular switch' between apoptosis and autophagy that has these pathways in common.

The theory that TCM plays an active role in cancer treatment by inducing autophagy has been studied. The medicinal mushroom, Ganoderma lucidum, is one of the most esteemed natural products that has been used as a TCM. G. lucidum triterpene extract (GLT) has been demonstrated to suppress the phosphorylation of p38 MAPK, and to induce autophagy and Beclin 1 expression in colon cancer cells (82). In addition, pheophorbide-a $(\mathrm{Pa})$ is an active component isolated from a Chinese herb and $\mathrm{Pa}$-based photodynamic therapy (Pa-PDT) has demonstrated antitumor effects by activating mitochondria-mediated apoptosis and ERK-mediated autophagy in MDA-MB-231 cells (83). Moreover, as mTOR plays a central role in the autophagy pathway, TCMs that are able to induce tumor cell death through mTOR may potentially induce autophagy (Table V). Other TCMs mentioned in Table IV may also potentially participate in the regulation of autophagy. Furthermore, flavokawain B, a novel chalcone from Alpinia pricei Hayata with potent anticancer activity, significantly inhibits the growth of colon cancer cells, thus providing novel insights into the molecular mechanisms underlying its apopototic activity. Flavokawain B provokes G2/M accumulation in addition to autophagy, and it also acts through ROS generation and GADD153 upregulation to regulate the expression of Bcl-2 family members, thereby inducing mitochondrial dysfunction and apoptosis in HCT116 cells (84). Furthermore, licorice, a common Chinese medicinal herb with antitumor activity, is able to induce autophagy by downregulating $\mathrm{Bcl}-2$ and inhibiting the mTOR pathway (85).

Previously, it was considered that cell death induced by IR is apoptotic, while autophagy is an alternative cell death pathway that is induced by mTOR inhibitors and upregulated when apoptosis is defective. The novel response of cancer cells to IR or chemotherapy has been demonstrated to increase the resistance of cancer cells to various apoptotic stimuli. Upregulation of autophagy by inhibitors of caspase-3 and mTOR enhanced radiotherapy responses in a mouse model of lung cancer. Combined Bcl-2/mTOR inhibition was observed to lead to enhanced radiosensitivity via induction of apoptosis and autophagy in vitro and in a lung cancer xenograft model; this is a potential therapeutic strategy for enhancing radiation therapy in patients with non-small cell lung cancer. Bromodeoxyuridine (BrdU) was found to enhance and modify radiation-induced cell death by accelerating the increase in the $\mathrm{Bax} / \mathrm{Bcl}-2$ ratio in non-irradiated cells, subsequently increasing radiation-induced apoptosis and/or autophagy depending on the radiation dosage (76,79-81). Moreover, the cell wall skeleton of Mycobacterium bovis bacillus Calmette-Guérin (BCG/CWS) is an effective antitumor immunotherapy agent; BCG/CWS plus IR-induced autophagy and cell death were predominantly mediated by the generation of ROS. This suggests that BCG/CWS in combination with IR is a promising therapeutic strategy for enhancing radiation therapy in colon cancer cells through the induction of autophagy (82). However, once a tumor has formed, autophagy inhibition may be a therapeutic target for radiosensitization and chemosensitization. At present, the relationship between cancer and deregulated autophagy appears to be complex and must be disentangled by further in-depth study (83).

Z-VAD, a broad-spectrum caspase inhibitor, is a radiosensitizer in breast and lung cancer in vitro and in vivo. Caspase inhibition is proposed to have the potential to enhance the therapeutic ratio of radiation therapy in solid tumors. Therefore, clinical trials are required to determine the potential of this combination therapy in cancer patients. In addition, the autophagy inhibitors, 3-methyladenine (3-MA) and bafilomycin A1, may represent a new application of radiosensitization for malignant glioma cells $(85,86)$. Moreover, vitamin D or vitamin D analogs are involved in the radiosensitization of breast tumor cells mediated via autophagy, and also delay and attenuate the proliferative recovery that may be a preclinical indicator of disease recurrence (84). Furthermore, DNA-PK plays a key role in the DNA DSB repair induced by IR; inhibition of DNA-PK combined with IR is capable of 
inducing autophagy and radiosensitizing the malignant glioma cells, and may be promising as a new therapy for radiosensitizing tumors. Additionally, pharmacological inhibition of nuclear factor (NF) $-\kappa \mathrm{B}$ has been demonstrated to enhance cell damage and radiosensitization through autophagy in glioma cell lines $(87,88)$.

\section{Prospects}

Currently, the functions of TCMs in cancer cells and the relative underlying molecular mechanisms are not yet completely understood. The studies described in this review have indicated that TCMs, which are observed to have a radiosensitizing effect through mechanisms involving their apoptotic and autophagic properties, have the potential to be effective systemic radiosensitizers that may be used to amplify radiation-induced toxicity in tumor tissues. TCMs are able to exhibit anticancer roles by apoptosis and autophagy, through mTOR and the Bcl-2 family pathway. Although the molecular mechanisms underlying autophagy are not yet fully understood, modulators of autophagy may have a number of potential benefits; promoters of autophagy may induce autophagy-mediated cell death in types of cancer with a high threshold to apoptosis. Certain TCM herbs may be used as radioprotectors that are able to ameliorate radiation-induced toxicity in normal tissue in cancer patients undergoing radiotherapy. We propose further evaluation of TCM for its radiosensitive and radioprotection potential in a clinical setting.

\section{Acknowledgements}

This study was supported by grants from the National Natural Science Foundation of China (NSFC; Grant Nos. 30770649 and 30970682).

\section{References}

1. Gao JL, Shi JM, He K, et al: Yanhusuo extract inhibits metastasis of breast cancer cells by modulating mitogen-activated protein kinase signaling pathways. Oncol Rep 20: 819-824, 2008.

2. Pang X, Yi Z, Zhang J, et al: Celastrol suppresses angiogenesismediated tumor growth through inhibition of AKT/mammalian target of rapamycin pathway. Cancer Res 70: 1951-1959, 2010.

3. Wang Y, Dong H, Zhu M, et al: Icariin exterts negative effects on human gastric cancer cell invasion and migration by vasodilator-stimulated phosphoprotein via Racl pathway. Eur J Pharmacol 635: 40-48, 2010.

4. Pan TL, Hung YC, Wang PW, et al: Functional proteomic and structural insights into molecular targets related to the growth inhibitory effect of tanshinone IIA on HeLa cells. Proteomics 10: 914-929, 2010.

5. Yuxian X, Feng T, Ren L and Zhengcai L: Tanshinone II-A inhibits invasion and metastasis of human hepatocellular carcinoma cells in vitro and in vivo. Tumori 95: 789-795, 2009.

6. Duan H, Luan J, Liu Q, Yagasaki K and Zhang G: Suppression of human lung cancer cell growth and migration by berbamine. Cytotechnology 62: 341-348, 2010.

7. Chen D, Yao WJ, Zhang XL, et al: Effects of Gekko sulfated polysaccharide-protein complex on human hepatoma SMMC-7721 cells: inhibition of proliferation and migration. J Ethnopharmacol 127: 702-708, 2010.

8. Liu F, Wang JG, Wang SY, Li Y, Wu YP and Xi SM: Antitumor effect and mechanism of Gecko on human esophageal carcinoma cell lines in vitro and xenografted sarcoma 180 in Kunming mice. World J Gastroenterol 14: 3990-3996, 2008.

9. Hsu SC, Ou CC, Li JW, et al: Ganoderma tsugae extracts inhibit colorectal cancer cell growth via $\mathrm{G}(2) / \mathrm{M}$ cell cycle arrest. J Ethnopharmacol 120: 394-401, 2008.
10. Zhang YK, Zhang XH, Li JM, Sun de S, Yang Q and Diao DM: A proteomic study on a human osteosarcoma cell line Saos-2 treated with diallyl trisulfide. Anticancer Drugs 20: 702-712, 2009.

11. Hsu HY, Hau DM and Lin CC: Effects of kuei-pi-tang on cellular immunocompetence of gamma-irradiated mice. Am J Chin Med 21: 151-158, 1993.

12. Yang MW, He MD and Li MZ: Effects of zaizhang-I, a traditional Chinese herbal medicine, on hematopoietic recovery from radiation injury in mice. J Tongji Med Univ 14: 224-226, 1994.

13. Ohnishi Y, Yasumizu R, Fan HX, et al: Effects of juzen-taiho-toh (TJ-48), a traditional Oriental medicine, on hematopoietic recovery from radiation injury in mice. Exp Hematol 18: 18-22, 1990.

14. Fujii Y, Imamura M, Han M, et al: Recipient-mediated effect of a traditional Chinese herbal medicine, ren-shen-yang-rong-tang (Japanese name: ninjin-youei-to), on hematopoietic recovery following lethal irradiation and syngeneic bone marrow transplantation. Int J Immunopharmacol 16: 615-622, 1994.

15. Chen WC, Hau DM, Chen KT, Wang MI and Lin IH: Protective effects of Gynostemma pentaphyllum in gamma-irradiated mice. Am J Chin Med 24: 83-92, 1996.

16. Hsu HY and Lin CC: A preliminary study on the radioprotection of mouse hematopoiesis by dang-gui-shao-yao-san. J Ethnopharmacol 55: 43-48, 1996.

17. Chen WC, Hau DM and Lee SS: Effects of Ganoderma lucidum and krestin on cellular immunocompetence in gamma-ray-irradiated mice. Am J Chin Med 23: 71-80, 1995.

18. Lee SE, Oh H, Yang JA, et al: Radioprotective effects of two traditional Chinese medicine prescriptions: si-wu-tang and si-jun-zi-tang. Am J Chin Med 27: 387-396, 1999.

19. Lawenda BD: Response to "Radiation therapeutic gain and Asian botanicals," by Stephen Sagar. Integr Cancer Ther 9: 14-15, 2010.

20. Reeve VE, Allanson M, Arun SJ, Domanski D and Painter N: Mice drinking goji berry juice (Lycium barbarum) are protected from UV radiation-induced skin damage via antioxidant pathways. Photochem Photobiol Sci 9: 601-607, 2010.

21. Liu FY, Wang JN, Yu SD, Wang B and Zhang JD: Effect of panaxatriol on hematogenesis and granulocyte-macrophage colony stimulating factor in radiation injured mice. Saudi Med J 28: 1791-1795, 2007.

22. Kim SH, Lee SE, Oh H, et al: The radioprotective effects of bu-zhong-yi-qi-tang: a prescription of traditional Chinese medicine. Am J Chin Med 30: 127-137, 2002.

23. Li CR, Zhou Z, Zhu D, Sun YN, Dai JM and Wang SQ: Protective effect of paeoniflorin on irradiation-induced cell damage involved in modulation of reactive oxygen species and the mitogen-activated protein kinases. Int J Biochem Cell Biol 39: 426-438, 2007.

24. Kim S and Chung JH: Berberine prevents UV-induced MMP-1 and reduction of type I procollagen expression in human dermal fibroblasts. Phytomedicine 15: 749-753, 2008.

25. Chiu TM, Huang CC, Lin TJ, Fang JY, Wu NL and Hung CF: In vitro and in vivo anti-photoaging effects of an isoflavone extract from soybean cake. J Ethnopharmacol 126: 108-113, 2009.

26. Dai AW, Li ZY, Wang LH, Li SY and Yang H: Effect of Yangyin Humo Decoction on oral mucomembranous reaction to radiotherapy. Chin J Integr Med 15: 303-306, 2009.

27. Wang ZW, Zhou JM, Huang ZS, et al: Aloe polysaccharides mediated radioprotective effect through the inhibition of apoptosis. J Radiat Res 45: 447-454, 2004.

28. Lu Y, Wu LQ, Dong Q and Li CS: Experimental study on the effect of Kang-Lai-Te induced apoptosis of human hepatoma carcinoma cell HepG2. Hepatobiliary Pancreat Dis Int 8: 267-272, 2009.

29. Wang GY, Lv QH, Dong Q, Xu RZ and Dong QH: Berbamine induces Fas-mediated apoptosis in human hepatocellular carcinoma HepG2 cells and inhibits its tumor growth in nude mice. J Asian Nat Prod Res 11: 219-228, 2009.

30. Zhang Z, Wang S, Qiu H, Duan C, Ding K and Wang Z: Waltonitone induces human hepatocellular carcinoma cells apoptosis in vitro and in vivo. Cancer Lett 286: 223-231, 2009.

31. Sung B, Park B, Yadav VR and Aggarwal BB: Celastrol, a triterpene, enhances TRAIL-induced apoptosis through the down-regulation of cell survival proteins and up-regulation of death receptors. J Biol Chem 285: 11498-11507, 2010.

32. Li W, Xie L, Chen Z, et al: Cantharidin, a potent and selective PP2A inhibitor, induces an oxidative stress-independent growth inhibition of pancreatic cancer cells through G2/M cell-cycle arrest and apoptosis. Cancer Sci 101: 1226-1233, 2010. 
33. Fang SC, Hsu CL, Lin HT and Yen GC: Anticancer effects of flavonoid derivatives isolated from Millettia reticulata Benth in SK-Hep-1 human hepatocellular carcinoma cells. J Agric Food Chem 58: 814-820, 2010

34. Lin VC, Chou CH, Lin YC, et al: Osthole suppresses fatty acid synthase expression in HER2-overexpressing breast cancer cells through modulating Akt/mTOR pathway. J Agric Food Chem 58: 4786-4793, 2010

35. Deng R, Tang J, Xie BF, et al: SYUNZ-16, a newly synthesized alkannin derivative, induces tumor cells apoptosis and suppresses tumor growth through inhibition of PKB/AKT kinase activity and blockade of AKT/FOXO signal pathway. Int J Cancer 127: 220-229, 2010

36. Shen JK, Du HP, Yang M, Wang YG and Jin J: Casticin induces leukemic cell death through apoptosis and mitotic catastrophe. Ann Hematol 88: 743-752, 2009.

37. Jin CY, Kim GY and Choi YH: Induction of apoptosis by aqueous extract of Cordyceps militaris through activation of caspases and inactivation of Akt in human breast cancer MDA-MB-231 cells. J Microbiol Biotechnol 18: 1997-2003, 2008.

38. Chiang PC, Lin SC, Pan SL, et al: Antroquinonol displays anticancer potential against human hepatocellular carcinoma cells: a crucial role of AMPK and mTOR pathways. Biochem Pharmacol 79: 162-171, 2010

39. Yang CJ, Huang YJ, Wang CY, et al: Antiproliferative and antitumorigenic activity of Toona sinensis leaf extracts in lung adenocarcinoma. J Med Food 13: 54-61, 2010.

40. Mi JX, Wang GF, Wang HB, et al: Synergistic antitumoral activity and induction of apoptosis by novel pan Bcl-2 proteins inhibitor apogossypolone with adriamycin in human hepatocellular carcinoma. Acta Pharmacol Sin 29: 1467-1477, 2008.

41. Wang N, Tang LJ, Zhu GQ, et al: Apoptosis induced by baicalin involving up-regulation of P53 and bax in MCF-7 cells. J Asian Nat Prod Res 10: 1129-1135, 2008

42. Kim DW, Ahan SH and Kim TY: Enhancement of arsenic trioxide $\left(\mathrm{As}_{2} \mathrm{O}_{3}\right)$-mediated apoptosis using berberine in human neuroblastoma SH-SY5Y cells. J Korean Neurosurg Soc 42: 392-399, 2007.

43. Su CL, Lin TY, Lin CN and Won SJ: Involvement of caspases and apoptosis-inducing factor in bufotalin-induced apoptosis of Hep 3B cells. J Agric Food Chem 57: 55-61, 2009.

44. Xie H, Qin YX, Zhou YL, et al: GA3, a new gambogic acid derivative, exhibits potent antitumor activities in vitro via apoptosis-involved mechanisms. Acta Pharmacol Sin 30: 346-354 2009.

45. Xu X, Liu Y, Wang L, et al: Gambogic acid induces apoptosis by regulating the expression of $\mathrm{Bax}$ and $\mathrm{Bcl}-2$ and enhancing caspase-3 activity in human malignant melanoma A375 cells. Int J Dermatol 48: 186-192, 2009.

46. Li DD, Wu XQ, Tang J, Wei XY and Zhu XF: ON-III inhibits erbB-2 tyrosine kinase receptor signal pathway and triggers apoptosis through induction of Bim in breast cancer cells. Cancer Biol Ther 8: 739-743, 2009.

47. Lai WW, Yang JS, Lai KC, et al: Rhein induced apoptosis through the endoplasmic reticulum stress, caspase- and mitochondriadependent pathways in SCC-4 human tongue squamous cancer cells. In Vivo 23: 309-316, 2009.

48. Xiao X, Bai P, Bui Nguyen TM, et al: The antitumoral effect of Paris Saponin I associated with the induction of apoptosis through the mitochondrial pathway. Mol Cancer Ther 8: $1179-1188,2009$.

49. Xu Y, Ge R, Du J, et al: Corosolic acid induces apoptosis through mitochondrial pathway and caspase activation in human cervix adenocarcinoma HeLa cells. Cancer Lett 284: 229-237, 2009.

50. Yang HL, Chen SC, Chen CS, Wang SY and Hseu YC: Alpinia pricei rhizome extracts induce apoptosis of human carcinoma $\mathrm{KB}$ cells via a mitochondria-dependent apoptotic pathway. Food Chem Toxicol 46: 3318-3324, 2008.

51. Qi F, Li A, Zhao L, et al: Cinobufacini, an aqueous extract from Bufo bufo gargarizans Cantor, induces apoptosis through a mitochondria-mediated pathway in human hepatocellular carcinoma cells. J Ethnopharmacol 128: 654-661, 2010.

52. Tang YJ, Yang JS, Lin CF, et al: Houttuynia cordata Thunb extract induces apoptosis through mitochondrial-dependent pathway in HT-29 human colon adenocarcinoma cells. Oncol Rep 22: 1051-1056, 2009.

53. Lu YY, Chen TS, Qu JL, Pan WL, Sun L and Wei XB: Dihydroartemisinin (DHA) induces caspase-3-dependent apoptosis in human lung adenocarcinoma ASTC-a-1 cells. J Biomed Sci 16: 16, 2009.
54. Chen CA, Chang HH, Kao CY, Tsai TH and Chen YJ: Plumbagin, isolated from Plumbago zeylanica, induces cell death through apoptosis in human pancreatic cancer cells. Pancreatology 9: 797-809, 2009.

55. Kim HG, Song H, Yoon DH, et al: Cordyceps pruinosa extracts induce apoptosis of HeLa cells by a caspase dependent pathway. J Ethnopharmacol 128: 342-351, 2010

56. Efferth T, Giaisi M, Merling A, Krammer PH and Li-Weber M: Artesunate induces ROS-mediated apoptosis in doxorubicinresistant T leukemia cells. PLoS One 2: e693, 2007.

57. Wu F, Hu Y, Long J, et al: Cytotoxicity and radiosensitization effect of TRA-8 on radioresistant human larynx squamous carcinoma cells. Oncol Rep 21: 461-465, 2009.

58. Ortiz T, Burguillos MA, Lopez-Lluch G, et al: Enhanced induction of apoptosis in a radio-resistant bladder tumor cell line by combined treatments with X-rays and wortmannin. Radiat Environ Biophys 47: 445-452, 2008.

59. Du XL, Jiang T, Wen ZQ, Gao R, Cui M and Wang F: Silencing of heat shock protein 70 expression enhances radiotherapy efficacy and inhibits cell invasion in endometrial cancer cell line. Croat Med J 50: 143-150, 2009

60. Efimova EV, Liang H, Pitroda SP, et al: Radioresistance of Stat1 over-expressing tumour cells is associated with suppressed apoptotic response to cytotoxic agents and increased IL6-IL8 signalling. Int J Radiat Biol 85: 421-431, 2009.

61. Chiou SH, Kao CL, Chen YW, et al: Identification of CD133-positive radioresistant cells in atypical teratoid/rhabdoid tumor. PLoS One 3: e2090, 2008

62. Guoan X, Hanning W, Kaiyun C and Hao L: Adenovirus-mediated siRNA targeting Mcl-1 gene increases radiosensitivity of pancreatic carcinoma cells in vitro and in vivo. Surgery 147: 553-561, 2010.

63. Hara T, Omura-Minamisawa M, Kang Y, Cheng C and Inoue T: Flavopiridol potentiates the cytotoxic effects of radiation in radioresistant tumor cells in which p53 is mutated or Bcl-2 is overexpressed. Int J Radiat Oncol Biol Phys 71: 1485-1495, 2008.

64. Ezekwudo D, Shashidharamurthy R, Devineni D, Bozeman E, Palaniappan R and Selvaraj P: Inhibition of expression of anti-apoptotic protein $\mathrm{Bcl}-2$ and induction of cell death in radioresistant human prostate adenocarcinoma cell line (PC-3) by methyl jasmonate. Cancer Lett 270: 277-285, 2008.

65. Wang TJ, Liu ZS, Zeng ZC, et al: Caffeine enhances radiosensitization to orthotopic transplant LM3 hepatocellular carcinoma in vivo. Cancer Sci 101: 1440-1446, 2010.

66. You ZY, Zhao Y, Liu F, Zhang YD and Wang JJ: The radiosensitization effects of Endostar on human lung squamous cancer cells H-520. Cancer Cell Int 10: 17, 2010.

67. Che SM, Zhang XZ, Hou L and Song TB: Cyclooxygenase-2 inhibitor NS398 enhances radiosensitivity of radioresistant esophageal cancer cells by inhibiting AKT activation and inducing apoptosis. Cancer Invest 28: 679-688, 2010.

68. Liu J, Zhang J, Wang X, et al: HIF-1 and NDRG2 contribute to hypoxia-induced radioresistance of cervical cancer Hela cells. Exp Cell Res 316: 1985-1993, 2010.

69. Gao L, Li F, Dong B, et al: Inhibition of STAT3 and ErbB2 suppresses tumor growth, enhances radiosensitivity, and induces mitochondria-dependent apoptosis in glioma cells. Int J Radiat Oncol Biol Phys 77: 1223-1231, 2010.

70. Chen X, Wong P, Radany E and Wong JY: HDAC inhibitor, valproic acid, induces p53-dependent radiosensitization of colon cancer cells. Cancer Biother Radiopharm 24: 689-699, 2009.

71. Yu J and Zhang L: PUMA, a potent killer with or without p53. Oncogene 27 (Suppl 1): S71-S83, 2008.

72. Mi J, Bolesta E, Brautigan DL and Larner JM: PP2A regulates ionizing radiation-induced apoptosis through Ser46 phosphorylation of p53. Mol Cancer Ther 8: 135-140, 2009.

73. Wang R, Lin F, Wang X, et al: Suppression of Bcl-xL expression by a novel tumor-specific RNA interference system inhibits proliferation and enhances radiosensitivity in prostatic carcinoma cells. Cancer Chemother Pharmacol 61: 943-952, 2008.

74. Ho SY, Chen WC, Chiu HW, Lai CS, Guo HR and Wang YJ: Combination treatment with arsenic trioxide and irradiation enhances apoptotic effects in U937 cells through increased mitotic arrest and ROS generation. Chem Biol Interact 179: 304-313, 2009.

75. Lee TK, Johnke RM, Allison RR, O'Brien KF and Dobbs LJ, Jr: Radioprotective potential of ginseng. Mutagenesis 20: 237-243, 2005. 
76. Rubinsztein DC, DiFiglia M, Heintz N, et al: Autophagy and its possible roles in nervous system diseases, damage and repair. Autophagy 1: 11-22, 2005.

77. Adi-Harel S, Erlich S, Schmukler E, et al: Beclin 1 self-association is independent of autophagy induction by amino acid deprivation and rapamycin treatment. J Cell Biochem 110: 1262-1271, 2010.

78. Maiuri MC, Criollo A and Kroemer G: Crosstalk between apoptosis and autophagy within the Beclin 1 interactome. EMBO J 29: 515-516, 2010

79. Pimkina J, Humbey O, Zilfou JT, Jarnik M and Murphy ME: ARF induces autophagy by virtue of interaction with Bcl-xl. J Biol Chem 284: 2803-2810, 2009.

80. Moretti L, Attia A, Kim KW and Lu B: Crosstalk between $\mathrm{Bak} / \mathrm{Bax}$ and mTOR signaling regulates radiation-induced autophagy. Autophagy 3: 142-144, 2007.

81. Zalckvar E, Berissi H, Mizrachy L, et al: DAP-kinase-mediated phosphorylation on the $\mathrm{BH} 3$ domain of beclin 1 promotes dissociation of beclin 1 from Bcl-XL and induction of autophagy. EMBO Rep 10: 285-292, 2009

82. Thyagarajan A, Jedinak A, Nguyen $\mathrm{H}$, et al: Triterpenes from Ganoderma lucidum induce autophagy in colon cancer through the inhibition of p38 mitogen-activated kinase (p38 MAPK). Nutr Cancer 62: 630-640, 2010.

83. Bui-Xuan NH, Tang PM, Wong CK and Fung KP: Photo-activated pheophorbide-a, an active component of Scutellaria barbata enhances apoptosis via the suppression of ERK-mediated autophagy in the estrogen receptor-negative human breast adenocarcinoma cells MDA-MB-231. J Ethnopharmacol 131: 95-103, 2010.
84. Kuo YF, Su YZ, Tseng YH, Wang SY, Wang HM and Chueh PJ: Flavokawain B, a novel chalcone from Alpinia pricei Hayata with potent apoptotic activity: Involvement of ROS and GADD153 upstream of mitochondria-dependent apoptosis in HCT116 cells. Free Radic Biol Med 49: 214-226, 2010.

85. Yo YT, Shieh GS, Hsu KF, Wu CL and Shiau AL: Licorice and licochalcone-A induce autophagy in LNCaP prostate cancer cells by suppression of Bcl-2 expression and the mTOR pathway. J Agric Food Chem 57: 8266-8273, 2009.

86. Law BY, Wang M, Ma DL, et al: Alisol B, a novel inhibitor of the sarcoplasmic/endoplasmic reticulum $\mathrm{Ca}^{2+}$ ATPase pump, induces autophagy, endoplasmic reticulum stress, and apoptosis. Mol Cancer Ther 9: 718-730, 2010.

87. Kim KW, Hwang M, Moretti L, Jaboin JJ, Cha YI and Lu B: Autophagy upregulation by inhibitors of caspase- 3 and mTOR enhances radiotherapy in a mouse model of lung cancer. Autophagy 4: 659-668, 2008.

88. Kim KW, Moretti L, Mitchell LR, Jung DK and Lu B: Combined Bcl-2/mammalian target of rapamycin inhibition leads to enhanced radiosensitization via induction of apoptosis and autophagy in non-small cell lung tumor xenograft model. Clin Cancer Res 15: 6096-6105, 2009. 